\title{
Seasonal size variation in the predatory cladoceran Bythotrephes cederstroemii in Lake Michigan
}

\author{
STEFFEN BURKHARDT \\ Department of Biology, Natural Science Building, The University of Michigan, Ann Arbor, MI 48109, U.S.A.
}

Present address: Alfred Wegener Institute for Polar and Marine Research, Postfach 1201 61, Columbusstrasse, W-27568 Bremerhaven, Germany

\begin{abstract}
SUMMARY
1. Dry weight, body length and spine length were measured for the exotic cladoceran Bythotrephes cederstroemii collected from offshore and inshore stations in southeastern Lake Michigan. Average dry weight of each developmental stage exhibited seasonal variation by a factor of more than 5 .

2. Mean dry weight of Bythotrephes was closely correlated with water temperature. Contrary to the inverse relationship between water temperature and body size frequently observed for other invertebrates, the dry weight of Bythotrephes increased at higher ambient temperatures.

3. No significant correlation was observed between abundances of major zooplankton taxa and the dry weight of Bythotrephes. An indirect effect of temperature on prey consumption may cause seasonal variation in dry weight of Bythotrephes in Lake Michigan.

4. Distances between adjacent pairs of barbs, added to the caudal spine with each moult, are significantly shorter in Bythotrephes which produce resting eggs. Less material investment in the exoskeleton of sexually reproducing females was observed in favour of growth and reproduction.
\end{abstract}

\section{Introduction}

Over the past decades, Lake Michigan has experienced repeated introductions of exotic species. Some invaded the Laurentian Great Lakes by natural ingress, such as the alewife (Alosa pseudoharengus Wilson) (Miller, 1957; Brown, 1972). Others were introduced by fish management practices, for example by salmonid stocking efforts since the 1960s (Walters et al., 1980; Stewart, Ritchell \& Crowder, 1981). Bythotrephes cederstroemii Schödler (Cladocera: Cercopagidae) and the zebra mussel (Dreissena polymorpha Pallas) represent the most recent invasions of the Great Lakes ecosystem by novel species (Bur, Klarer \& Krieger, 1986; Lange \& Cap, 1986; Lehman, 1987; Cullis \& Johnson, 1988; Robert, 1990).

Bythotrephes is native to Northern Europe and Asia. Relatively little was known about its life history, population dynamics and ecological importance in pelagic food webs prior to its invasion of North America. To date, length-dry weight regressions, as well as data on seasonal abundance and vertical migration patterns, have been reported for the animals (Garton \& Berg, 1990; Lehman, 1987, 1991). However, no complete record of seasonal variation in dry weight over an entire growing season existed for Bythotrephes. Information on seasonal variation in body size provides basic knowledge for a variety of studies. First, size measurements contribute to an understanding of the phenotypic plasticity of the animals, i.e. to what extent the growth of Bythotrephes is affected by environmental factors. Second, in studies of trophic dynamics, seasonal variations in body mass of Bythotrephes affect its contribution to total zooplankton biomass estimates based on abundance of the animals at a given time. Finally, size of Bythotrephes plays an important role in predatorprey interactions. Studies of the feeding behaviour 
of young fish demonstrate that the caudal spine of Bythotrephes serves as an effective structural defence against predation, increasing handling time and the probability of rejection by young planktivores (Barnhisel, 1991a). With increasing spine length the probability of rejecting a Bythotrephes increases and the probability of ingesting a Bythotrephes decreases (Barnhisel, 1991b). In addition, the spine influences foraging decisions of young fish and increasing spine length can induce aversion to Bythotrephes in larger fish.

In this study, patterns of seasonal variation in dry weight are reported for Bythotrephes collected at an inshore and an offshore station in southeastern Lake Michigan. To explain the observed trends, variation in dry weight was compared with variation in ambient temperature and abundances of major zooplankton taxa at any given sampling date. A comparison of inshore and offshore populations of the animals is used to evaluate the potential impact of fish predation on the size variation of Bythotrephes. In addition to dry weight, body length, total spine length and distances between adjacent pairs of lateral spines (barbs) were measured. Material investment in growth of the caudal spine appears to be related to the mode of reproduction (sexual versus parthenogenetic) of Bythotrephes.

\section{Materials and Methods}

Bythotrephes was collected with a Puget Sound closing net $(1 \mathrm{~m}$ diameter) of $130 \mu \mathrm{m}$ mesh size from $20 \mathrm{~m}$ vertical hauls in southeastern Lake Michigan during seven research cruises on the R/V Laurentian between 20 June and 29 September 1990 and during four cruises in 1991. Animals were obtained from a reference station $(z=100 \mathrm{~m}) 36 \mathrm{~km}$ offshore from Grand Haven, MI at $43^{\circ} \mathrm{N} 86^{\circ} 40^{\prime} \mathrm{W}$ at five sampling dates in 1990 (6 July, 16-19 July, 30 July-3 August, 10 September, 29 September) and at all 1991 cruises (27-28 June, 15-20 July, 30-31 July, 12-15 August). Furthermore, Bythotrephes was collected with vertical net hauls at a $20 \mathrm{~m}$ deep inshore station near Grand Haven, at $43^{\circ} \mathrm{N} 86^{\circ} 16.3^{\prime} \mathrm{W}$ during three research cruises in 1990 (16-19 July, 30 July-3 August, 29 September). On 20 June 1990, an offshore population of Bythotrephes had not yet been developed and inshore abundances were low. Therefore, samples were taken inshore with a $1 \mathrm{~m}^{2}$ Tucker Trawl of $300 \mu \mathrm{m}$ mesh size.
Water temperatures were recorded with a conductivity-temperature-depth system (CTD, Seabird) to a precision of $0.0001^{\circ} \mathrm{C}$ and were tabulated at $1 \mathrm{~m}$ intervals. Epilimnetic temperatures are reported as mean stratum temperatures from the surface to the thermocline. For sampling dates prior to stratification, mean stratum temperatures for the top $20 \mathrm{~m}$ are used in calculations.

After collection, Bythotrephes were transferred to Petri dishes from the solid 2-L PVC cod end with forceps applied to their chitinous spines, rinsing the animals three times in GF-F filtered Lake Michigan water. Bythotrephes were then placed individually in Teflon on dry ice and were frozen for later analysis. Dry weight of freeze-dried specimens was measured individually with a Cahn 29 automatic electrobalance to a precision of $1 \mu \mathrm{g}$. Gender and reproductive stage of the animals was determined microscopically. In addition to Bythotrephes which were frozen immediately, dry weights of animals used in $\mathrm{P}$ excretion experiments in summer 1990 (Burkhardt, 1991) were included in the results. On three cruises in July 1990, parthenogenetic females which carried embryos of the black eye stage, an indicator of the final period of embryo development (Yurista, 1992), were kept until hatching. The neonates were freeze-dried and weighed individually.

To avoid size selection biases, all Bythotrephes collected in each net tow were used for weight measurements. At low abundances early in the growing season, several vertical hauls were necessary to obtain a sufficiently large sample size.

Age-specific morphological stages were distinguished by the number of lateral spines (paired barbs; Fig. 1) at the base of the chitinous caudal appendage. Neonates possess one pair of barbs. Typically, a new pair is added at each moult to a total of two pairs in adult males, three pairs in adult females produced parthenogenetically, and four pairs in females produced sexually (Ischreyt, 1934; Yurista, 1992). However, Bythotrephes may occasionally moult without adding barbs so that the number of barbs does not necessarily correspond to actual instars. Therefore, the terms developmental stage or barb stage are used in this paper according to the age-related number of paired barbs. Laboratory observations by Yurista (1992) indicate a number of dissimilarities in the embryonic and post-embryonic development of Bythotrephes compared with that of other Cladocera. A distinct difference in the num- 


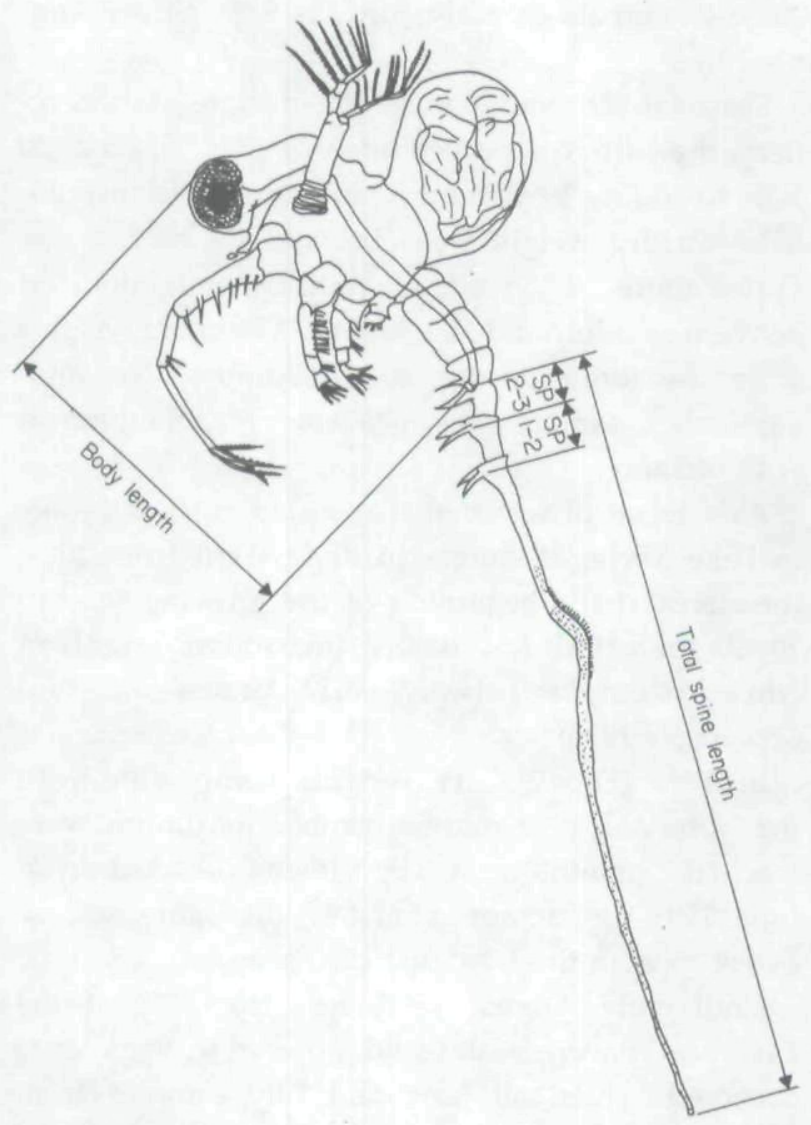

Fig. 1 Measurements of body length and spine length parameters of Bythotrephes.

ber of instar stages to primaparity exists between parthenogenetically (stages $1-3$ ) and sexually (stages 1-4) produced Bythotrephes. Females with two pairs of barbs are typically immature and have only occasionally been observed bearing eggs or embryos (Yurista, 1992; personal observations).

Correlations between mean dry weight of the developmental stages and environmental variables were analysed by linear regressions of dry weight on temperature (1990 and 1991) and the abundance of major zooplankton taxa (1990). Epilimnetic temperature and abundance of zooplankton were treated as independent variables. Zooplankton taxa were chosen according to sizes which represent potential prey of Bythotrephes, as was observed in feeding experiments (Burkhardt, 1991). Copepods included the copepodid stages $(\mathrm{C} 1-6)$ of the genera Diaptomus, Cyclops, and Epischura. Herbivorous Cladocera included Bosmina longirostris, Eubosmina coregoni and the Daphnia species D. galeata mendotae, D. pulicaria, and $D$. retrocurva.
In addition to dry weight, several length parameters of Bythotrephes were measured for samples collected between 18 July and 19 September 1989 . Specimens preserved in a sugar-formalin solution (Haney \& Hall, 1973) were used for all length measurements. At high abundances in late summer, subsamples were obtained with a Folsom Plankton Splitter (for details on the sampling procedure, see Lehman et al., 1990).

Most of the animals were preserved in a characteristic position, the head bent downward as illustrated in Fig. 1. In accordance with length measurements by Ischreyt (1934), body length was defined as the distance from the distal rim of the eye to the anus, located between the proximal pair of lateral spines. In addition, total spine length, defined as the distance from the anus to the tip of the spine, and distances between adjacent lateral spines were measured (Fig. 1).

All females which possessed a complete tail spine were used for length measurements. At sampling dates when Bythotrephes were rare, several subsamples were analysed to obtain minimum sample sizes of approximately thirty for each barb stage. For animals collected on 19 September 1989 , only seventeen intact specimens of stage 1 and fifteen specimens of stage 2 were available for length measurements.

Systat version 5.0 was used for statistical analyses. Lilliefors tests were performed to test for normality of the sample distributions. Non-normal distributions were log-transformed. Randomized subsamples were used in two-way ANOVA to obtain equal subclass sizes.

\section{Results}

Fig. 2 illustrates the seasonal variation in body mass of Bythotrephes in offshore Lake Michigan during 1990 and 1991, and from 1990 inshore samples. Mean dry weight for animals of each developmental stage is plotted for each of the sampling dates. Stage 4 represents the fourth instar of sexually produced offspring (Yurista, 1992), observed only early in the growing season in Lake Michigan.

Differences in dry weights within each stage across all sampling dates, presented in Fig. 2, are significant (two-way ANOVA, $P<0.001$ ). No evidence for sampling date $\times$ barb stage interaction was observed in some cases, for example, when stage 3 was excluded from the analysis of 1990 data. However, considering 


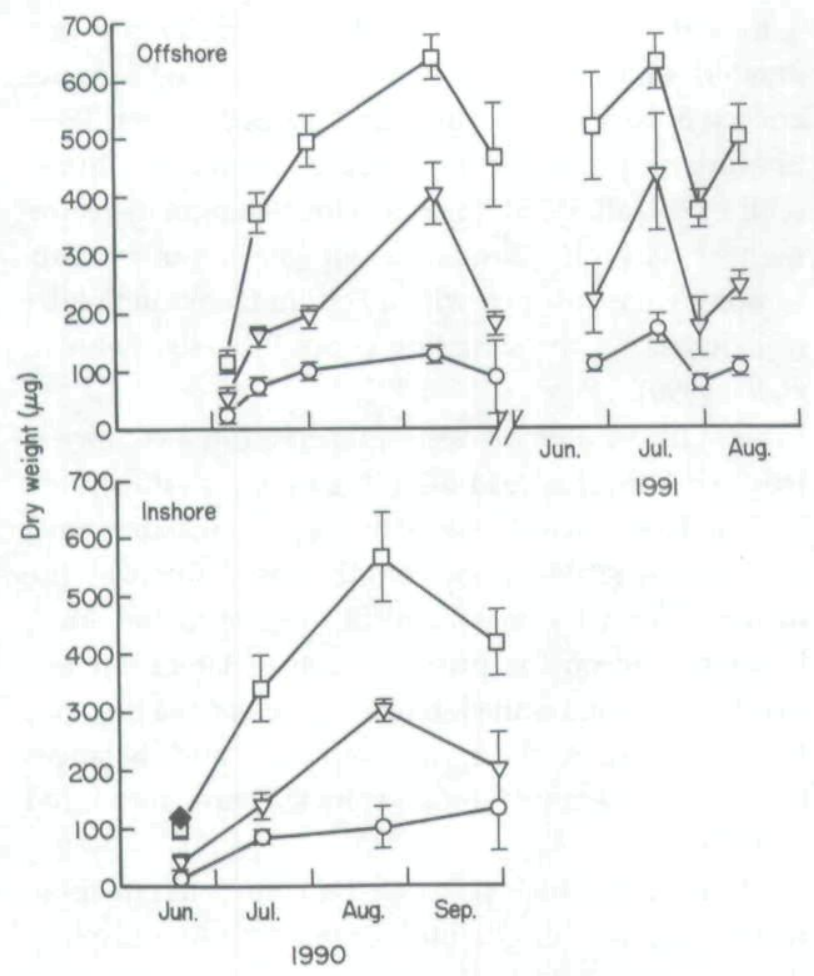

Fig. 2 Seasonal variation in mean dry weight $( \pm 95 \% \mathrm{CL})$ of Bythotrephes, collected at nine sampling dates between 6 July and 12 August 1991 from an offshore station and at four sampling dates between 20 June and 29 September 1990 from an inshore station in southeastern Lake Michigan. Stages 1-3 represent the three post-embryonic developmental stages.

Stage 4 is characteristic of sexually produced females, observed Only at the onset of the growing season. $\odot$, Stage $1 ; \nabla$, Stage 2; $\square$, Stage $3, \bullet$, Stage 4 .

the three barb stages simultaneously, sampling date $\times$ barb stage interaction across $1990(P=0.003)$ and $1991(P=0.01)$ samples was significant, as will be discussed below.

At the offshore station, mean dry weight within each stage increased more than five-fold between 6 July and 10 September 1990 , when maximum weights of some specimens exceeded $1000 \mu \mathrm{g}$. Reaching a peak between August and late September, average weights on 29 September dropped to a level similar to early August. Size variation is also reflected in embryonic size. Mean weight of neonates at hatching increased by a factor similar to the weight increase of the three developmental stages. In early July 1990 , neonates hatched at a dry weight of $13.2 \mu \mathrm{g}$ $(\mathrm{SE}=0.4 \mu \mathrm{g}, n=57)$. In early August, on the other hand, neonates hatched at a dry weight $(72.6 \mu \mathrm{g}$, $\mathrm{SE}=19 \mu \mathrm{g}, n=51)$ greater than the mean weight of stage 2 animals in early July $(54.9 \mu \mathrm{g}, \mathrm{SE}=7.4 \mu \mathrm{g}$, $n=12$ ).

Seasonal size variation at the inshore station reflects the pattern observed offshore (Fig. 2). From 20 June to 16 July 1990 , more than a three-fold increase in mean dry weight was observed for each stage. Furthermore, dry weights approximately doubled between mid-July and late August. Maximum weights were measured during 20-26 August. No midSeptember sample was available for comparison with offshore.

As a result of seasonal size variation, Bythotrephes in Lake Michigan ranges in dry weight from $10 \mu \mathrm{g}$ (neonates at the beginning of the growing season, 20-23 June 1990) to $>1000 \mu \mathrm{g}$ (maximum weights of adult Bythotrephes between early August and midSeptember 1990).

In 1991 (Fig. 2), dry weights comparable with the observed 1990 mid-September maximum were reached 2 months earlier. Specimens collected on 28 June 1991 are of approximately the same size as Bythotrephes in the 1 August 1990 sample.

Until early August 1990, less than $5 \%$ of the Bythotrephes were males and no resting eggs were observed. Thus, all June and July samples from that year represent dry weights of parthenogenetic females. At both sampling stations, the proportion of males increased from $4 \%$ (16-19 July) to $32 \%$ (10 September) and dropped to $16 \%$ in late September. Between mid-July and mid-September 1990, 18-22\% of the adult females carried resting eggs, but no resting eggs were found at the offshore station on 29 September. In 1991, significant numbers of sexual females were collected on 17 July (15\% of adult females) and 12 August (8\%). The proportion of males in the samples ranged from $14 \%$ (17 July) to $26 \%$ (12 August).

Dry weight differences between inshore and offshore populations of Bythotrephes at two sampling dates (16 July and 29 September 1990; Fig. 2) were compared by independent $t$-tests. Due to variability in dry weight within each developmental stage, size differences between two-barb (inshore versus of offshore) and between three-barb animals are not significant $(P>0.05)$. The only significant difference in mean dry weight $(P<0.05)$ was observed between juvenile animals (stage 1) on 29 September 1990. At both sampling dates, one-barb Bythotrephes weighed less at the offshore station. 
A comparison of size ranges of the three developmental stages provides information about the nature of the age-specific morphological stages. Little overlap between barb stages indicates that the groups should represent distinct instars. In contrast, if moults occurred without addition of a new pair of barbs, a considerable overlap in size ranges would be expected. Fig. 3 presents stage-specific size ranges as box plots (Wilkinson, 1990) for three offshore samples collected at the beginning (6 July), in the middle (1 August), and at the end (29 September) of the 1990 growing season. On 6 July and 29 September 1990, little overlap occurs between the barb stages. On 1 August 1990, size overlap is more pronounced. The widest range in dry weight was observed in threebarb animals.

Seasonal variations in dry weight of Bythotrephes and epilimnetic temperature are illustrated in Fig. 4 for 1990 and 1991. Changes in dry weight are paralleled by changes in temperature, reaching a maximum in mid-September 1990 followed by a marked decline on 29 September 1990. As temperature increases to $21.8^{\circ} \mathrm{C}$ on 17 July 1991 , mean dry weights reach values similar to those observed on 11 September 1990 at $21.3^{\circ} \mathrm{C}$. Due to mixing events between 17 July and 30 July 1991 it is believed that dry weights of Bythotrephes collected on 30 July 1991 are not representative of epilimnetic temperatures at that time (see Discussion). Therefore, data from 30 July 1991 are not included in Fig. 4.

As illustrated in Fig. 5, the increase in dry weight of Bythotrephes from early July to mid-September is also reflected in an increase in abundances of the major taxa of herbivorous Cladocera. However, despite a continued increase in Daphnia abundance
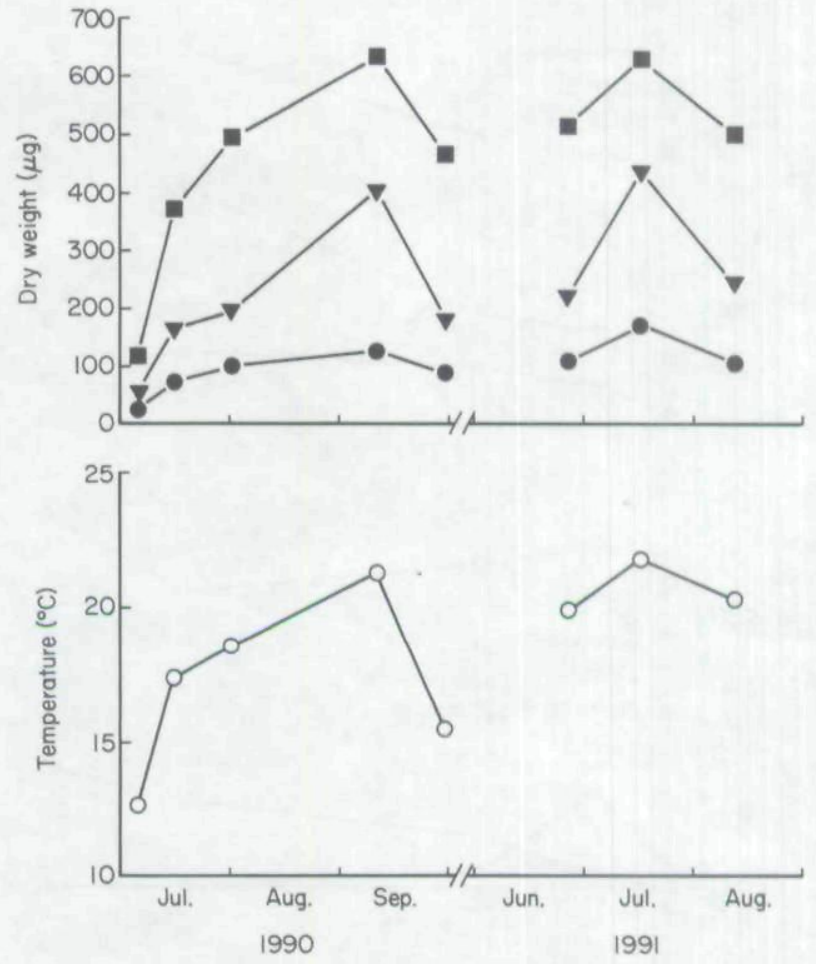

Fig. 4 Seasonal variation in mean biomass of the three developmental stages of Bythotrephes and epilimnetic temperature in 1990 and 1991. 30 July 1991 not included (see Discussion). $\bullet$, Stage 1; $\mathbf{v}$, Stage 2; $\mathbf{m}$, Stage 3.

between 10 September and 29 September 1990, a decline in mean dry weight of Bythotrephes was observed. Bosmina and Eubosmina did not constitute a significant portion $(<2 \%)$ of the Cladocera after 1 August 1990. The number of copepodids does not exhibit a seasonal pattern that could be correlated with variation in body mass of Bythotrephes.

Linear regressions of dry weight on temperature
Fig. 3 Box plots of Bythotrephes dry weight, illustrating stage-specific size ranges for three sampling dates in 1990 at an offshore station in southeastern Lake Michigan. Asterisk indicates outside value.
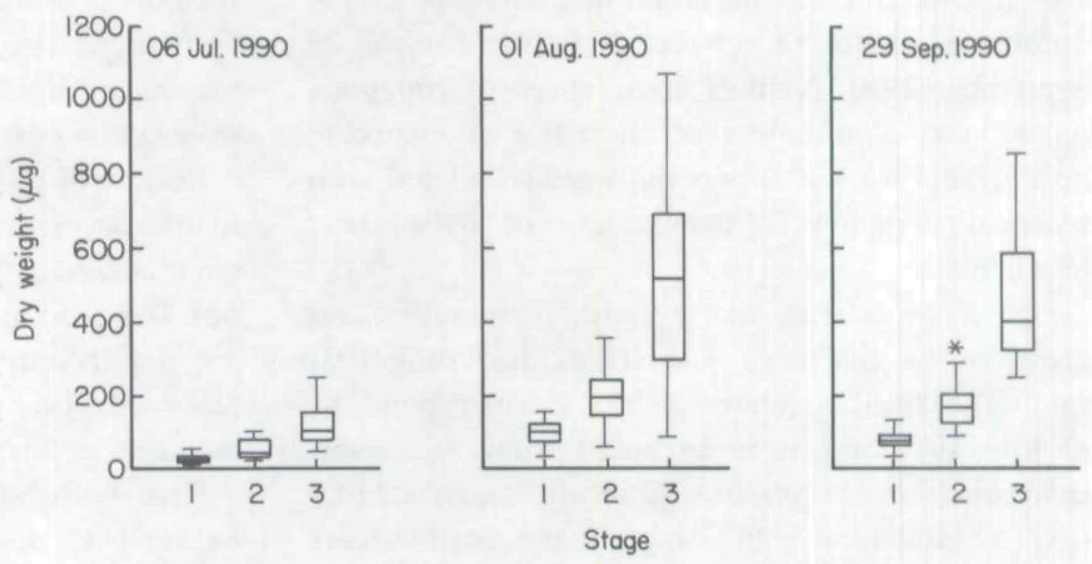

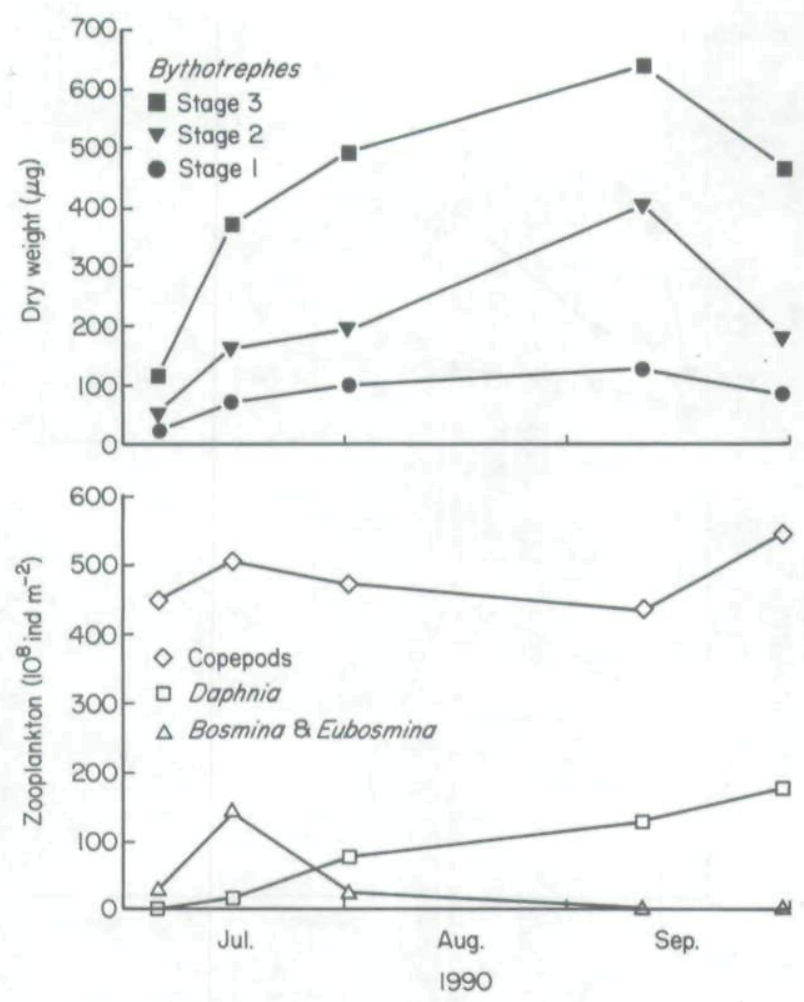

Fig. 5 Seasonal variation in mean biomass and abundance of copepods (Diaptomus, Cyclops and Epischura) and Cladocera (Daphnia, Bosmina and Eubosmina) in southeastern Lake Michigan 1990.

and abundance of zooplankton were calculated for 1990 data, treating temperature and the abundances of major zooplankton taxa as independent variables. Fig. 6 indicates a close, positive correlation of dry weight with temperature at each developmental stage $\left(r_{1}=0.945, r_{2}=0.908, r_{3}=0.927\right.$; each $\left.P<0.05\right)$. On the other hand, no significant correlation between dry weight and abundance of Cladocera was found $\left(r_{1}=0.596, r_{2}=0.431, r_{3}=0.649\right.$; each $\left.P>0.20\right)$ which was mainly due to the continued increase in the number of Cladocera between 10 September and 29 September 1990. Neither abundances of copepods nor pooled abundances of all major zooplankton taxa (Cladocera and copepods) were correlated with seasonal variation in dry weight of Bythotrephes $(P>0.50)$.

Fig. 7 represents dry weight-temperature regressions for the three barb stages, including 1991 data. The filled symbols at $20.7^{\circ} \mathrm{C}$ correspond to 30 July 1991 and were excluded from regression analyses (see Discussion). Due to larger sample size, the statistical significance of the positive cor-
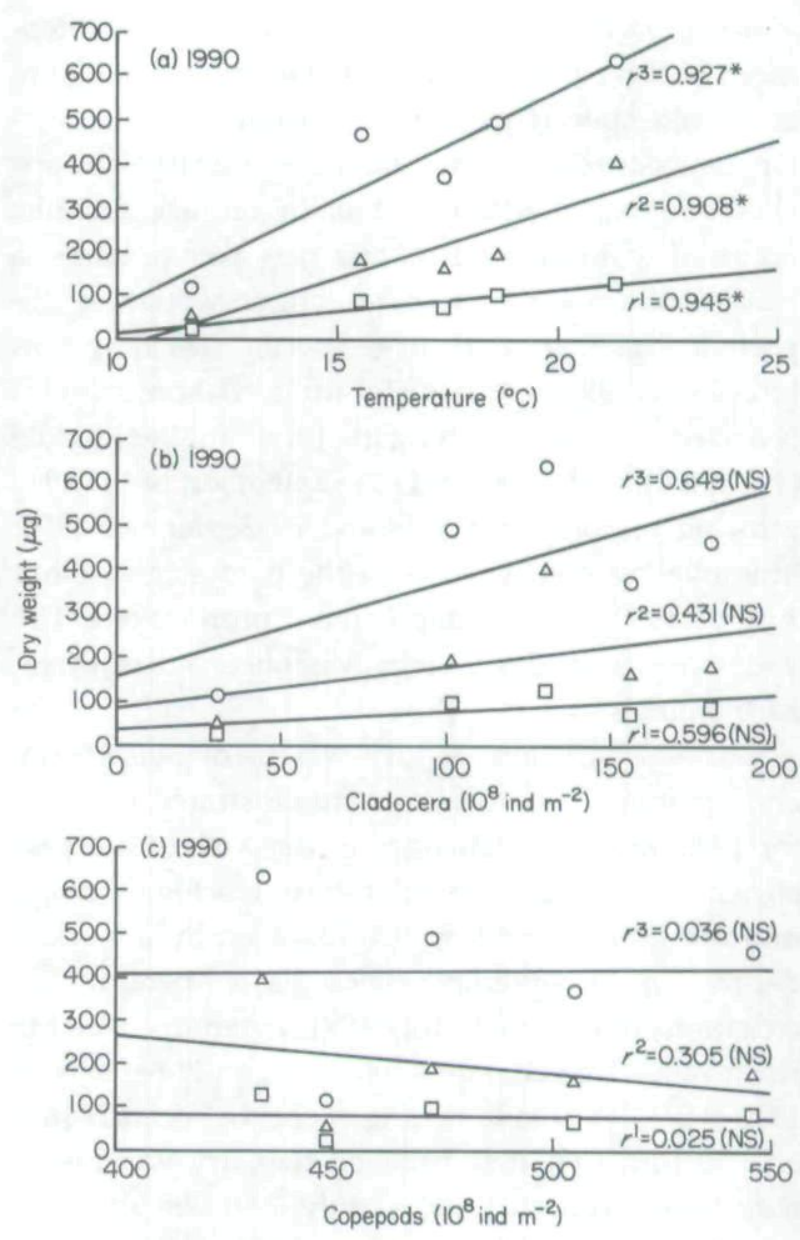

Fig. 6 Linear regressions of mean dry weight of Bythotrephes on (a) epilimnetic temperature, (b) abundance of Cladocera (Daphnia, Bosmina and Eubosmina), (c) abundance of copepods (Diaptomus, Cyclops and Epischura). Symbols represent mean dry weight of one-barb ( $\square)$, two-barb $(\Delta)$, and three-barb $(\circ)$ Bythotrephes, collected at five sampling dates between 6 July and 29 September 1990 from offshore Lake Michigan. Asterisks indicate statistical significance at the 0.05 level.

relation between individual dry weights and mean epilimnetic temperature was improved $(P<0.005)$. Statistical significance $(P<0.015)$ is maintained, even when including data points from 30 July 1991.

Results of body length and spine length measurements of preserved samples collected in 1989 are summarized in Table 1. Sample sizes prior to July are not large enough for statistical comparisons and are not included in the results. Two trends were observed in length parameters of samples collected between 18 July and 20 September 1989 .

First, both body length and total spine length of Bythotrephes development stages increased signifi- 


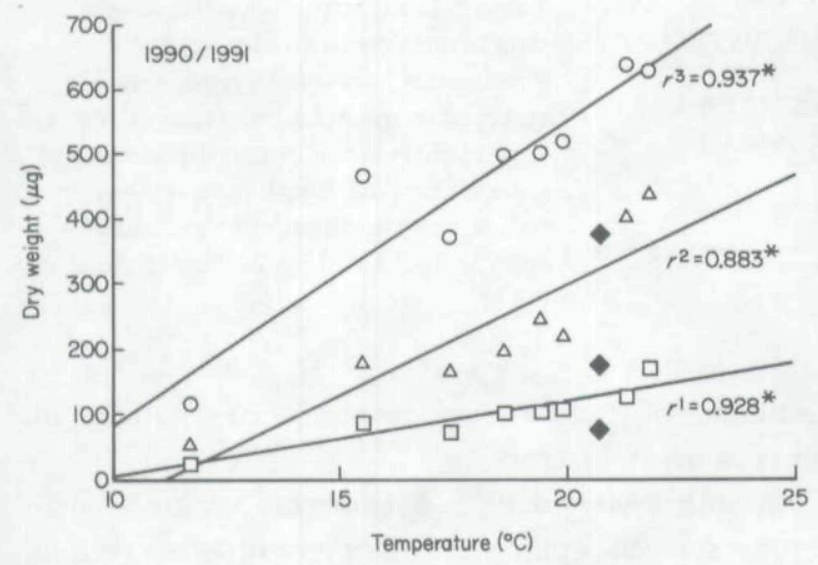

Fig. 7 Linear regressions of mean dry weight of one-barb (ㅁ), two-barb $(\Delta)$, and three-barb $(0)$ Bythotrephes on epilimnetic temperature (1990 and 1991). Filled symbols represent dry weights of the three stages on 30 July 1991 and were not used for calculation of regression equations (see Discussion).

cantly $(P<0.05)$ from mid-July to early August. Mean epilimnetic temperatures at the offshore reference station reached maximum values $\left(20.1-20.6^{\circ} \mathrm{C}\right)$ during August 1989, coinciding with the greatest body length of Bythotrephes. Thus, length measurements represented a similar positive correlation with temperature as was observed in 1990 and 1991 weight measurements.

Second, the spacing pattern of lateral pairs of spines was related to reproductive stage (Table 2). A comparison of parthenogenetic females carrying embryos with resting egg-producing Bythotrephes, collected at the same time, indicated significantly $(P<0.05)$ shorter total length of the tail spine of females carrying resting eggs.

Results presented in Table 2 are representative of females of the third stage, collected during two cruises in August 1989. While the length from the terminal pair of lateral spines to the tip of the tail spine is the same, the distances between adjacent pairs of lateral spines (Sp 1-2 and Sp 2-3, Fig. 1) are significantly shorter in females carrying resting eggs.

\section{Discussion}

\section{Seasonal variation in dry weight}

A several-fold increase in mean dry weight of each developmental stage of Bythotrephes can occur within less than 2 weeks. This indicates immediate response to changes in environmental factors. Garton \& Berg (1990) ascribe variation in life history traits of Bythotrephes cederstroemii among the Laurentian Great Lakes to physiological responses to different environmental conditions.

Yurista (1992) observed that parthenogenetic young of Bythotrephes do not develop from yolk-rich eggs, as do other Cladocera. Their asexual eggs are initially small and inconspicuous, when deposited into the mother's brood chamber without a shell. During development the embryos increase in size and greatly distend the brood pouch (MordukhaiBoltovskaya, 1957; Yurista, 1992). This feature may account for the wide range of dry weight observed in three-barb animals.

Table 1 Body length and total spine length of sugar-formalin-preserved Bythotrephes cederstroemii collected between 18 July and 1 October 1989 at an offshore reference station in Lake Michigan. Numbers refer to mean, standard deviation, and sample size

\begin{tabular}{|c|c|c|c|c|c|c|}
\hline \multirow[b]{2}{*}{ Date } & \multicolumn{3}{|c|}{ Body length (mm) } & \multicolumn{3}{|c|}{ Total spine length $(\mathrm{mm})$} \\
\hline & $\begin{array}{c}\text { 1-barb (SD) } \\
n\end{array}$ & $\begin{array}{c}\text { 2-barb (SD) } \\
n\end{array}$ & $\begin{array}{c}\text { 3-barb (SD) } \\
n\end{array}$ & $\begin{array}{c}\text { 1-barb (SD) } \\
n\end{array}$ & $\begin{array}{c}\text { 2-barb (SD) } \\
n\end{array}$ & $\begin{array}{c}\text { 3-barb (SD) } \\
n\end{array}$ \\
\hline 18 July & $\begin{array}{c}1.77(0.28) \\
38\end{array}$ & $\begin{array}{c}2.29(0.23) \\
33\end{array}$ & $\begin{array}{c}2.90(0.38) \\
59\end{array}$ & $\begin{array}{c}5.44(0.59) \\
38\end{array}$ & $\begin{array}{c}6.47(0.44) \\
33\end{array}$ & $\begin{array}{c}8.00(0.65) \\
59\end{array}$ \\
\hline 7 August & $\begin{array}{c}2.28(0.36) \\
47\end{array}$ & $\begin{array}{c}2.85(0.51) \\
43\end{array}$ & $\begin{array}{c}3.29(0.32) \\
38\end{array}$ & $\begin{array}{c}5.83(0.33) \\
47\end{array}$ & $\begin{array}{c}6.73(0.56) \\
43\end{array}$ & $\begin{array}{c}7.89(0.78) \\
38\end{array}$ \\
\hline 22 August & $\begin{array}{c}2.01(0.24) \\
29\end{array}$ & $\begin{array}{c}2.83(0.49) \\
34\end{array}$ & $\begin{array}{c}3.25(0.37) \\
79\end{array}$ & $\begin{array}{c}5.85(0.48) \\
29\end{array}$ & $\begin{array}{c}6.86(0.57) \\
34\end{array}$ & $\begin{array}{c}7.92(0.67) \\
79\end{array}$ \\
\hline 19 Sept. & $\begin{array}{c}1.98(0.26) \\
17\end{array}$ & $\begin{array}{c}2.52(0.41) \\
15\end{array}$ & $\begin{array}{c}3.06(0.42) \\
27\end{array}$ & $\begin{array}{c}5.82(0.39) \\
17\end{array}$ & $\begin{array}{c}6.97(0.34) \\
15\end{array}$ & $\begin{array}{c}8.29(0.63) \\
27\end{array}$ \\
\hline
\end{tabular}




\begin{tabular}{lllllll}
\hline & Body & Spine total & Sp 2-3 & Sp 1-2 & Sp(term-tip) & $n$ \\
\hline Embryos & $3.22(0.28)$ & $8.18(0.87)$ & $1.43(0.30)$ & $1.10(0.20)$ & $5.67(0.59)$ & 19 \\
Rest eggs & $3.28(0.35)$ & $7.62(0.61)$ & $1.04(0.35)$ & $0.95(0.22)$ & $5.64(0.45)$ & 45 \\
$P$ (ind. $t$-test) & 0.510 & 0.004 & $<0.001$ & 0.009 & 0.860 & \\
\hline
\end{tabular}

Standard deviation in parentheses.

Little overlap in the size spectrum of different developmental stages supports the assumption that barb stage is to a large extent representative of the actual instar development. The extent to which iteroparity occurs in stage 3 animals is not known. However, it is important to notice that the release of neonates coincides with a weight loss to levels similar to animals at their second moult (Lehman, unpublished). A much greater material investment in their offspring than in the mass of their own body tissue appears to be characteristic of reproductive females. Therefore, the presence of multiple adult instars would not have a great influence on the discussion of temperature effects on instar development. The greater size overlap on 1 August 1990 indicates that the likelihood of moults without barb addition increases during mid-summer. However, highly significant differences in mean dry weight are maintained and justify the grouping of age-specific stages by the number of barbs.

It should be noted that the correlation analysis of dry weight with temperature and zooplankton abundances involves a time lag, given by the age of Bythotrephes at sampling. However, the entire life cycle of Cladocera (from hatching to primaparity) under abundant food at $20^{\circ} \mathrm{C}$ is approximately 7 days (Lynch, 1980). Yurista (1992) measured postembryonic development times for Bythotrephes at $12.7^{\circ} \mathrm{C}$ and embryonic development times at temperatures ranging from $10^{\circ} \mathrm{C}$ to $21.5^{\circ} \mathrm{C}$. Based on temperature dependency of embryonic growth, postembryonic development times can be extrapolated from $12.7^{\circ} \mathrm{C}$ to other temperatures. At temperatures encountered in offshore Lake Michigan after 6 July 1990 , Bythotrephes should reach primaparity in less than 9 days (Yurista, pers. comm.). At a temperature of $18^{\circ} \mathrm{C}$, midpoint age of the three instars is $1.6,4.4$ and 7.0 days. Therefore, it is believed that a comparison of dry weight with temperature and simultaneous zooplankton abundances represents a close
Table 2 Comparison of mean length parameters, measured for adult Bythotrephes (stage 3) carrying either embryos of the black eye stage or resting eggs in their brood pouch. Sp(term-tip) represents spine length from the terminal pair of barbs to the tip of the caudal spine. Sp 2-3 and Sp 1-2 are defined in Fig. 1 estimate of Bythotrephes' response to changes in environmental factors.

In both 1990 and 1991, Bythotrephes attained maximum size at epilimnetic temperatures exceeding $21^{\circ} \mathrm{C}$. In 1990 , thermal stratification was delayed until mid-July, whereas a mean epilimnetic temperature of almost $20^{\circ} \mathrm{C}$ was observed in the following year as early as 27 June 1991 . At that time, the three-barb stages were already as big as Bythotrephes collected on 1 August 1990 at the same offshore station.

The only exception to a close, positive correlation between temperature and dry weight was an unexpected large decrease in body mass between 17 July and 30 July 1991, revealing constraints of the correlation analysis: a lack of knowledge about the thermal history of the animals. Between the two sampling dates, upwelling decreased mean water temperature (top $15 \mathrm{~m}$ ) at the inshore station from $19.1^{\circ} \mathrm{C}$ to $13.4^{\circ} \mathrm{C}$. At the same time, the thermocline (defined as the stratum of steepest temperature gradient) at the offshore station was lowered by $3 \mathrm{~m}$. It is suggested that as a result of mixing events between 17 July and 30 July 1991 the animals were temporarily exposed to lower temperatures causing an exaggerated decrease in body mass. Dry weights on 30 July 1991 would not be representative of the epilimnetic temperature at that time. Thus, data from this sampling date are not included in Fig. 4 and in the regression analysis (Fig. 7).

No significant sampling date $\times$ barb stage interaction would be expected in a two-way ANOVA, if environmental factors affected growth equally at any age and if the different stage collected at one cruise had experienced identical environmental conditions during their development. However, barb stages would gain additional weight after a period of more favourable growth conditions. It is possible only to speculate about the causes of main effect and interaction terms in the two-way ANOVA, which indicates significant sampling date $\times$ barb stage interaction, if 
all three stages are considered simultaneously. Differences in thermal history may account for significant interaction. Likewise, differential mortality or differences in feeding history could lead to similar results. Experimental support has not yet been found for either of the potential effects.

Size variations in zooplankton have been studied frequently and attempts have been made to relate observed trends to environmental factors, in particular food (Vijverberg, 1976; Vidal, 1980; Klein Breteler \& Gonzales, 1982, 1988), temperature (Rzóska, 1927; Coker, 1933; Lock \& MacLaren, 1970; Culver, 1980), and fish predation (Wells, 1970; Warren et al., 1986). The use of field data complicates analysis of size variation patterns because parameters such as water temperature, food abundance, and planktivory are not independent of each other. Therefore, laboratory experiments have been performed in several studies (e.g. Coker, 1933; Vidal, 1980; Klein Breteler \& Gonzales, 1988) to quantify the impact of food availability relative to temperature on body growth. However, no general rule can be established to predict the relative importance of factors influencing variation in body size.

Laboratory experiments showed that the effect of temperature on dry weight of the marine calanoid copepods Calanus pacificus Brodsky and Pseudocalanus sp. was less than the effect of food concentration (Vidal, 1980). While mean dry weight of early copepodites was relatively unaffected by either food concentration or temperature, mean dry weight of late stages increased hyperbolically with food concentration and was inversely related to temperature. Coker (1933) suggested a direct rather than an indirect influence of temperature on size of copepods. In laboratory experiments with Cyclops viridis Jurine, C. serrulatus Fischer, and C. vernalis Fischer he found a marked inverse correlation of size with temperature whereas changes in food supply had comparatively little effect on total body size.

In Lake Michigan, seasonal variation in dry weight of Bythotrephes in 1990 indicates a closer correlation with epilimnetic temperature than with the abundance of any of the major zooplankton species. However, opposite to the inverse relationship between temperature and body size frequently observed for Cladocera (MacArthur \& Baillie, 1929; Culver, 1980) and Copepods (Coker, 1933; Lock \& MacLaren, 1970; Klein Breteler \& Gonzalez, 1988), Bythotrephes collected during the warm summer months in Lake Michigan were larger than individuals in spring and late autumn.

Two possible mechanisms could explain this trend: (1) a direct temperature effect due to optimum growth of Bythotrephes at temperatures of approximately $20^{\circ} \mathrm{C}$, or (2) an indirect effect of temperature on growth, because epilimnetic temperature, abundance of prey, and prey consumption rates are not independent of each other. Rzóska (1927) ascribes smaller body size of C. strenuus Fischer during spring, autumn, and winter in Lunzer See to suboptimal temperatures permitting only slow ontogenic development. On the other hand, Vidal (1980) found that the food concentration at which maximum dry weights of calanoid copepods were attained increased with increasing temperature, indicating an indirect effect of temperature on body growth.

Mordukhai-Boltovskaia (1958) reported that temperature had a marked effect on feeding in Leptodora and Bythotrephes. Maximum prey consumption rates of Bythotrephes increased from 9 prey day ${ }^{-1}$ at $10-15^{\circ} \mathrm{C}$ to $25-30$ prey day $^{-1}$ at $15-20^{\circ} \mathrm{C}$. Furthermore, estimates of the predatory impact of Bythotrephes collected in 1990, based on mass balance equations, indicate a marked increase in individual prey consumption rates of Bythotrephes during the warmer summer months (Burkhardt, 1991). Thus, greater prey consumption rates of Bythotrephes at warmer temperatures appear to be important in contributing to seasonal variation in animal weight.

Size of first reproduction (SFR) of zooplankton species, calculated from the length distribution among ovigerous females, is often used to interpret potential causes of size variation (e.g. Culver, 1980). However, in contrast to other Cladocera, egg deposition in the brood pouch of Bythotrephes is not easily observable because the eggs are initially small and inconspicuous (Mordukhai-Boltovskaya, 1957; Yurista, 1992). Consequently, no data are available to characterize SFR of Bythotrephes in field samples.

Field data on dry weight of Bythotrephes, temperature and abundance of the major zooplankton taxa indicate that each developmental stage of Bythotrephes reaches maximum body weight when herbivorous Cladocera species are present in large numbers and temperatures approach $20^{\circ} \mathrm{C}$. However, laboratory experiments are needed to separate direct and indirect effects of temperature from the effect of prey 
abundance on growth. It is obvious that an interpretation of the observed size variation pattern of Bythotrephes is necessarily speculative, as no mechanism has yet been tested in the laboratory.

Changes in the size distribution of zooplankton can be caused by the predatory impact of planktivorous fish (Brooks \& Dodson, 1965). Inshore and offshore abundances of fish vary seasonally and are to a large extent influenced by water temperature (e.g. Jude et al., 1975). It is difficult to quantify the predatory impact of fish in the inshore and offshore regions of Lake Michigan from numbers on fish abundances, which are derived from catch-per-uniteffort indices. However, a crude evaluation of the potential impact of fish predation on seasonal size variation of Bythotrephes can be made based on general trends of the distribution of fish.

Major planktivorous fish species in Lake Michigan include bloater (Coregonus hoyi Gill), alewife (Alosa pseudoharengus Wilson), and yellow perch (Perca flavescens Mitchill). While adult bloater prefers the colder, deeper waters during the summer months, alewife and yellow perch seek the warmer inshore waters for feeding, spawning and exploring of spawning areas (Jude et al., 1975). After the warm summer months, during which nearshore waters also experience the greatest number of species, inshore fish abundance declines progressively in September, October and November, as adults migrate to deeper waters (Jude et al., 1975).

Seasonal variation in dry weight of Bythotrephes, observed both offshore and inshore, is reflected in the body size of the animals. Size variation does not reveal any pattern that can be related to size-selective fish predation. At a time when the number of species and abundance of fish increases nearshore, mean dry weight of Bythotrephes at the inshore station increased by a factor of more than 2 between subsequent sampling dates. Although adult fish tend to migrate to deep water after August, size of two- and three-barb Bythotrephes declined on 29 September 1990 at the inshore station. This is not the expected pattern of body size change based on analogy with Daphnia (Tessier, Young \& Leibold, 1992).

Larval and young-of-the-year fish which may still be present in large numbers are not likely to prey on Bythotrephes. Feeding experiments showed that smaller fish had difficulties ingesting Bythotrephes (Barnhisel, 1991). Thus, temporal variation in body size of the predatory Cladoceran could not be accounted for by known gradients of planktivory. Chemical effects on morphogenesis are known in Cladocera (Dodson, 1989), but their effect here, if any, is unknown.

\section{Reduced spine growth in sexual females}

The correlation between spacing patterns of the lateral pairs of spines (barbs) and reproductive condition indicates an interesting difference between parthenogenetic and sexual females. The life cycle of Bythotrephes is typical for Cladocera, with cyclic parthenogenesis producing large numbers of offspring (Yurista, 1992). In Lake Michigan, the first production of sexual eggs coincides with peak abundances of the animals in August. The stimulus for sexuality is largely unknown. Crowding (Mortimer, 1935), photoperiod (Stross \& Hill, 1965), temperature (Mortimer, 1935), lack of food (Stuart, Tallmann \& Cooper, 1931), changes in food quality (von Dehn, 1950), or an abrupt decrease in ingestion rate (D'Abramo, 1980) have been suggested to stimulate production of resting eggs.

Although it is a crustacean, Bythotrephes does not moult its spine with the rest of the exoskeleton (Ischreyt, 1934; Yurista, 1992). In contrast, the caudal appendage grows between moults and an additional pair of lateral spines is typically added. Thus, growth of the tail spine could be considered a 'time axis' of development. Reduced distance between adjacent pairs of barbs would indicate faster development of resting egg-producing Bythotrephes. However, because parthenogenetic and sexual females experienced the same environmental conditions and both body length and length of the terminal part of the spine are equal, different rates of development seem unlikely.

On the other hand, the spacing pattern may be a result of differential growth and differential allocation of nutrients to growth or reproduction. The author suggests that material investment in chitinous structures such as the caudal spine is reduced in favour of production of resting eggs. In other words, less growth is allocated to a potential anti-predator device (Barnhisel, 1991a) in order to secure successful production of resting eggs.

The tendency toward longer distance between pairs of barbs in parthenogenetic females is consistent with results from Ischreyt's study (1934). In a com- 
parision of B. cederstroemii populations of two lakes, a greater proportion of sexual females was reflected in shorter distances between adjacent pairs of barbs. Garton \& Berg (1990) observed lower dry weights at a given spine length in Lake Erie samples, where sexual females were absent, than in Lake Superior, where $15 \%$ of the females carried sexual eggs. Longer tail spines of parthenogenetic animals may, in part, account for this observation.

\section{Length measurements}

In order to evaluate nutritional effects on seasonal size variation, length-dry weight regressions could provide useful information. The experimental protocol, however, required immediate freezing of most animals for further chemical analysis and to prevent losses of weight and phosphorus. The soft body tissue of Bythotrephes makes reliable length measurements of freeze-dried specimens impossible.

In contrast to dry weight measurements, body length measurements of sugar-formalin-preserved samples are more subjective. Due to the soft body tissue of Bythotrephes, measurements of body length depend on the relative position of the head to the tail spine of preserved specimen, as is indicated in Fig. 1, thus increasing the variance. As suggested by Berg \& Garton (1988), spine length is the most accurate measurement among other length parameters. However, spine length is not necessarily representative of body size. In a comparison of B. cederstroemii collected in two palearctic lakes, Ischreyt (1934) did not detect any difference in body size, whereas spines of one Bythotrephes population were significantly longer.

Body lengths of animals collected mid-July are significantly smaller than in early August 1989, when mean epilimnetic temperatures reach maximum values. These results are consistent for each of the three stages. For reasons mentioned above, no reliable length-weight regressions could have been calculated. However, the same trend was observed for body length as for dry weight measurements, indicating great phenotypic plasticity of Bythotrephes cederstroemii.

\section{Acknowledgments}

I am indebted to the Max Kade Foundation for financial support during this study. Additional financial assistance was provided by a Horace $\mathrm{H}$. Rackham Graduate School grant, the Peter Olaus Okkelberg Award, summer support by the Studienstiftung des Deutschen Volkes, and support as research assistant by grants from the U.S. National Science Foundation Biological Oceanography Program and Michigan Sea Grant to John Lehman. Special thanks go to John Lehman, who provided much encouragement for the development and execution of ideas. I am also grateful to George Kling and Earl Werner for helpful comments. Furthermore, I wish to acknowledge technical assistance by the crew of the R/V Laurentian during field operations.

\section{References}

Barnhisel D.R. (1991a) The caudal appendage of the cladoceran Bythotrephes cederstroemi as defense against young fish. Journal of Plankton Research, 13, 529-537.

Barnhisel D.R. (1991b) Zooplankton spine induces aversion in small fish predators. Oecologia, 88, 444-450.

Berg D.J. \& Garton D.W. (1988) Seasonal abundance of the exotic predatory cladoceran, Bythotrephes cederstroemi, in Western Lake Erie. Journal of Great Lakes Research, 14, 479-488.

Brooks J.L. \& Dodson S.I. (1965) Predation, body size, and composition of plankton. Science, 150, 28-35.

Brown E.H. (1972) Population biology of alewives, Alosa pseudoharengus, in Lake Michigan, 1949-70. Journal of the Fisheries Research Board of Canada, 29, 477-500.

Bur M.T., Klarer D.M. \& Krieger K.A. (1986) First records of a European cladoceran, Bythotrephes cederstroemi, in Lakes Erie and Huron. Journal of Great Lakes Research, 12, 144-146.

Burkhardt S. (1991) Phosphorus turnover, prey consumption, and size variation of the predatory cladoceran Bythotrephes cederstroemii. $\overline{\mathrm{MS}}$ thesis, University of Michigan, Ann Arbor.

Coker R.E. (1933) Influence of temperature on size of freshwater copepods (Cyclops). Internationale Revue der gesamten Hydrobiologie und Hydrographie, 29, 406-436.

Cullis K.I. \& Johnson G.E. (1988) First evidence of the cladoceran Bythotrephes cederstroemii Schödler in Lake Superior. Journal of Great Lakes Research, 14, 524-525.

Culver D. (1980) Seasonal variation in the sizes at birth and at first reproduction in Cladocera. Evolution and Ecology of Zooplankton Communities (Ed. W.C. Kerfoot), pp. 358-366. University Press Ńew England, NH.

D'Abramo L.R. (1980) Ingestion rate decrease as the stimulus for sexuality in populations of Moina macrocopa. Limnology and Oceanography, 25, 422-429.

Dodson S.I. (1989) The ecological role of chemical stimuli 
for the zooplankton: predator-induced morphology in Daphnia. Oecologia, 78, 361-367.

Garton D.W. \& Berg D.J. (1990) Occurrence of Bythotrephes cederstroemi (Schoedler 1877) in Lake Superior, with evidence of demographic variation within the Great Lakes. Journal of Great Lakes Research, 16, 148-152.

Haney J.F. \& Hall D.J. (1973) Sugar-coated Daphnia: a preservation technique for Cladocera. Limnology and Oceanography, 18, 331-333.

Ischreyt G. (1934) Über Bythotrephes cederstroemii Schödler. Internationale Revue der Gesamten Hydrobiologie, 31, 181-202.

Jude D.J., Tesar F.J., Tomlinson J.C., Miller T.J., Thurber N.J., Godun G.G. \& Dorr III J.A. (1975) Inshore Lake Michigan fish populations near the D.C. Cook nuclear power plant during preoperational years-1973, 1974. Special Report 71, Great Lakes Research Divison, University of Michigan, Ann Arbor, Michigan.

Klein Breteler W.C.M. \& Gonzalez S.R. (1982) Influence of cultivation and food concentration on body length of calanoid copepods. Marine Biology, 71, 157-161.

Klein Breteler W.C.M. \& Gonzalez S.R. (1988) Influence of temperature and food concentration on body size, weight and lipid content of two calanoid copepod species. Hydrobiologia, 167/168, 201-210.

Lange C. \& Cap R. (1986) Bythotrephes cederstroemi (Schödler). (Cercopagidae: Cladocera): A new record for Lake Ontario. Journal of Great Lakes Research, 12, 142-3.

Lehman J.T. (1987) Palearctic predator invades North American Great Lakes. Oecologia (Berlin), 74, 478-480.

Lehman J.T. (1991) Causes and consequences of the cladoceran dynamics in Lake Michigan. Implications of the species invasion by Bythotrephes. Journal of Great Lakes Research, 17, 437-445.

Lehman J.T., Bowers J.A., Gensemer R.W., Warren G.J. \& Branstrator D.K. (1990) Mysis relicta in Lake Michigan: abundances and relationships with their potential prey, Daphnia. Canadian Journal of Fisheries and Aquatic Sciences, 47, 977-983.

Lock A.R. \& MacLaren I.A. (1970) The effect of varying and constant temperatures on the size of a marine copepod. Limnology and Oceanography, 15, 638-640.

Lynch M. (1980) The evolution of cladoceran life histories. Quaterly Review of Biology, 55, 23-42.

MacArthur J.W. \& Baillie W.H.T. (1929) Metabolic activity and duration of life. 1 . Influence of temperature on longevity in Daphnia magna. Journal of Experimental Zoology, 53, 221-242.

Miller R.R. (1957) Origin and dispersal of the alewife. Alosa pseudoharengus, and the gizzard shad, Dorosoma cepedianum, in the Great Lakes. Transactions of the American Fisheries Society, 86, 97-111.

Mordukhai-Boltovskaia E.D. (1957) Parthenogenic breeding of Leptodora kindtii (Focke) and Bythotrephes.
Doklady Akademii Nauk SSSR, 122, 828-830.

Mordukhai-Boltovskaia E.D. (1958) Preliminary notes on the feeding of the carnivorous cladocerans Leptodora kindtii and Bythotrephes. Doklady Akademii Nauk SSSR, 122, 828-830.

Mortimer C.H. (1935) Untersuchungen ûber den Generationswechsel der Cladoceren. Naturwissenschaften, 23, 476-480.

Robert L. (1990) Zebra mussel invasion threatens U.S. waters. Science, 249, 1370-1372.

Rzóska J. (1927) Einige Beobachtungen über temporale Größenvariation bei Copepoden und einige andere Fragen ihrer Biologie. Internationale Revue der Hydrobiologie, 17, 99-114.

Stewart D.J., Kitchell J.F. \& Crowder L.B. (1981) Forage fishes and their salmonid predators in Lake Michigan. Transactions of the American Fisheries Society, 110, 751-63.

Stross R.G. \& Hill J.C. (1965) Diapause induction in Daphnia requires two stimuli. Science, 150, 1462-1464.

Stuart C.A., Tallmann J. \& Cooper H.J. (1931) Available food and crowding as factors influencing the sex of Moina macrocopa. 1. Physiological Zoology, 4, 581-593.

Tessier A.J., Young A. \& Leibold M. (1992) Population dynamics and body-size selection in Daphnia. Limnology and Oceanography, 37, 1-13.

Vidal J. (1980) Physioecology of zooplankton. 1. Effects of phytoplankton concentration, temperature, and body size on the growth rate of Calanus pacificus and Pseudocalanus sp. Marine Biology, 56, 111-134.

Vijverberg J. (1976) The effect of food quantity and quality on the growth, birth-rate and longevity of Daphnia hyalina Leydig. Hydrobiologia, 51, 99-108.

von Dehn M. (1950) Der Einfluß der Hefefettstoffe auf die Fortpflanzungsart von Moina rectirostris. Naturwissenschaften, 18, 429-430.

Walters C.J., Spangler G., Christie W.J., Manion D.J. \& Kitchell J.F. (1980) A synthesis of knowns, unknowns, and policy recommendations from the Sea Lamprey International Symposium. Canadian Journal of Fisheries and Aquatic Sciences, 37, 2202-2208.

Warren G.J., Evans M.S., Jude D.J. \& Ayers J.C. (1986) Seasonal variations in copepod size: effects of temperature, food abundance, and vertebrate predation. Journal of Plankton Research, 8, 841-853.

Wells L.R. (1970) Effects of alewife predation on zooplankton populations in Lake Michigan. Limnology and Oceanography, 15, 556-565.

Wilkinson L. (1990) Sygraph: The system for graphics. Systat, Inc. Evanston, II.

Yurista P.M. (1992) Embryonic and post-embryonic development in Bythotrephes cederstroemii. Canadian Journal of Fisheries and Aquatic Sciences, 49, 1118-1125.

(Manuscript accepted 16 August 1993) 
This document is a scanned copy of a printed document. No warranty is given about the accuracy of the copy. Users should refer to the original published version of the material. 